\title{
Comparison of bond strength between self-adhered and conventional composites
}

\author{
Adria Permana Putra*, Elin Karlina*, Renny Febrida* \\ Department of Dental Material Science and Technology Faculty of Dentistry Universitas Padjadjaran
}

\begin{abstract}
\end{abstract}
Bond strength towards dentine is a critical factor for composite restoration success. The purpose of this research was to obtain data on self-adhered composite bond strength to tooth dentine. This research was an experimental laboratory research that used 10 third molar teeth as samples. The teeth were prepared by thinning its mesial part until it reaches dentine layer. The sample was divided into two groups, each consisting of 5 teeth. In group I was applied self-adhered composite with Fusio ${ }^{\circledR}$ Liquid Dentine brand, whereas group II was applied conventional composite with Ivoclar Te-Econom Flow ${ }^{\circledR}$. The applied composite had a cylindrical shape with $6 \mathrm{~mm}$ diameter. The sample was then placed on the test arm. The shear bond strength test method then conducted on Universal Testing Machine (UTM). Obtained data was tested using Two-tails Independent t-Test $(\alpha=0,05)$. The results showed the average of self-adhered composite bond strength to dentine is $1,8878 \pm 0,2859 \mathrm{MPa}$ and conventional composite for 4,43552 \pm $0,49472 \mathrm{MPa}$. The data showed that the self-adhered composite bond strength to dentine is smaller than conventional composite. From this research can be concluded that there was bond strength difference between the self-adhered composite with conventional composites towards the tooth dentine.

Keywords: Bond strength, self-adhered composite, conventional composite, shear bond strength test

\section{INTRODUCTION}

In dental practice, dental restorations are one of the many actions that a dentist can take to treat the patient. The ingredients that have been used for many years and become the preferred material for posterior dental restorations at about the beginning of the $20^{\text {th }}$ century are amalgam..$^{1,2}$. However, this amalgam spillage material becomes a conflict over time due to its harmful and toxic mercury contents to the patient's body. In 1960, newly introduced materials were introduced which have better aesthetics than amalgam and are more biocompatible than amalgam known as composite. ${ }^{3,4}$ This material has much better characteristics than the previous material, so its use and development continues to this day. ${ }^{1,4}$

There are several composite hardening processes including light cure, as well as composites that harden themselves. ${ }^{1.4}$ In general, the composite application procedure consists of three steps, namely the application of acid etching, bonding agent, and the last composite. ${ }^{5}$

Theoretically, the composite bond with a tooth structure is a mechanical bond obtained from microporosity in the tooth structure. This microporosity is formed through acid etching procedures. Meanwhile, the resin that fills the microporosity is a bonding agent that will eventually polymerize with the composite, so that the composite blast has a binding force with a tooth structure. ${ }^{5,6}$

However, around 2009 composite technology is growing even further with the production of new composites. Manufacturers of self-adhered composites claim that, in it is already contained acid etching and bonding agent, so this composite can bond with tooth structure without needing acid etching step and bonding agent application. The self-adhered composite 
abbreviates the composite application procedure in general, thus automatically shortening the time required for performing dental restorations. Thus, the patient does not need to open the mouth for too long, so the patient can feel more comfortable in doing maintenance. ${ }^{7}$

The tensile strength between composite and dentin is one of the key factors for successful dental restoration. High-power composite loops can last longer and stronger on dental chewing, which can be compared with conventional type composites. The binding strength can be tested by the test method sliding bond strength or shear bond strength test. This test is often used for research on binding power, because it has an easy procedure and can provide an accurate simulation of binding strength. The purpose of this study was to obtain data of the bound strength between self-adhered composites with dentin teeth.

\section{METHODS}

This study was included in a laboratory experimental study to compare the magnitude of the binding strength of self-adhered composites with conventional composites to dental dentine. The sample used in this study was a fully erupted third molar with a good crown condition and can be made as preparation in accordance with the needs of research. The third molar was chosen because it was easy to obtain and had enough mesial area for research needs. Teeth applied conventional composites were used as controls.

The dental sampling criterion to be used in this study in more detail was to have normal size for third molar teeth, the crown was in good condition, can be prepared in accordance with the research needs, had perfect eruption, strong, not fragile. The total of samples used were 10 units divided into 2 groups, 5 for the treatment group and 5 for the control group.

The tools and research materials used in this research were tooth samples, micromotor for tooth preparation, bur diamond and diamond disc, self-adhered composite resin brand Fusio ${ }^{\circledR}$ Liquid Dentin. Batch No: 182869; expiration date: 05-2011, conventional composite resin Ivoclar TeEconom Flow $\circledast$. Batch No: L39313; Expiry date: 06-2012, plastic composite mold, and light cure unit Blue Light Mini $\circledast$.

\section{RESULTS}

This study was conducted on 10 third molar teeth that have been done preparation on the mesial. Preparation was done by attenuating the teeth until it reaches the dentine layer. The specimen was then divided into 2 groups consisting of 5 specimens each. In group I was applied a selfadhered composite and in group II was applied a conventional composite.

To obtain the data in the form of the strength of the composite binding to dentine teeth, the specimens were tested using the UTM® Lloyd LRX Plus with the help of the test arm (jig) in accordance with ISO: 11405 . The unit used was $\mathrm{MPa}$. Prior to the study, pre-liminary trials were performed using samples according to the study criteria. There were no significant constraints in the trial. Testing was performed immediately, after the specimen is made. This was done so that there would be no significant time difference in each specimen after polymerization and also to avoid any disturbing factors.

Table 1. Bonding strength of self-adhered composites and conventional composites

\begin{tabular}{|c|c|}
\hline \multicolumn{2}{|c|}{ Bonding strength (MPa) } \\
\hline Self-adhered composite & Conventional composite \\
\hline 1.7070 & 3.9408 \\
\hline 1.9477 & 4.6882 \\
\hline 1.7962 & 4.4631 \\
\hline 1.8344 & 4.4936 \\
\hline 2.1537 & 4.5919 \\
\hline
\end{tabular}

From Table 1 can be seen that the strength of the binding of self-adhered composite to dentine was $1.7070 \mathrm{MPa} ; 1.9477 \mathrm{MPa} ; 1.7962$ $\mathrm{MPa}$; 1.8344 ; MPa; $2.1537 \mathrm{MPa}$; with mean of $1.8878 \pm 0.2859 \mathrm{MPa}$. Whereas the magnitude of conventional composite binding strengths was 3.9408 MPa; $4.6882 \mathrm{MPa} ; 4.4631 \mathrm{MPa}$; $4.4631 \mathrm{MPa}$; $4.4936 \mathrm{MPa}$; $4.5919 \mathrm{MPa}$; with average $4.43552 \pm$ $0.49472 \mathrm{MPa}$.

The results were tested using t-statistic test, because this test was used to compare two groups of research samples. The type of statistical test $t$ chosen is a two-party t-test type test with two independent samples and has a comparable variation (Independent Sample t-test: two-tails). The results of the statistical tests performed were 
presented in Table 2 as a review for statistical analysis in this study.

In the table there is an absolute $t$ count of 16.88370128 and the value of $t$ distribution of 2.306004133. There was a significant difference in the bond between the self-adhered composite and the conventional composite to dentine.

Table 2. Statistical test results of the bond strength of composites

\begin{tabular}{|c|c|c|}
\hline \multicolumn{2}{|c|}{ Self-Adhered } & Conventional \\
\hline Average & 1.8878 & 4.43552 \\
\hline Variants & 0.029555395 & 0.084295927 \\
\hline Sample Amount & 5 & 5 \\
\hline Df & \multicolumn{2}{|c|}{8} \\
\hline t-countable & -16.88370128 \\
\hline $\begin{array}{c}\text { p-value (one } \\
\text { party) }\end{array}$ & $7.67651 \times 10^{-8}$ \\
\hline $\begin{array}{c}\text { t-distribution (one } \\
\text { party) }\end{array}$ & 1.859548033 \\
\hline $\begin{array}{c}\text { p-value (two } \\
\text { party) }\end{array}$ & $1.5353 \times 10^{-7}$ \\
\hline $\begin{array}{c}\text { t-distribution (two } \\
\text { party) }\end{array}$ & 2.306004133 \\
\hline
\end{tabular}

\section{DISCUSSION}

The binding strength test in this study refers to the international standard ISO: 11045 and some previous studies. ${ }^{8,9,10}$ In a previous study, the composite strength test on dentine was performed in various ways and methods. There are two commonly used methods, namely shear bond strength test and tensile bond strength. The difference between these two test methods is based on the UTM engine direction applying its strengths. ${ }^{8,9}$

The statistically significant average strength of binding of both materials showed a significant difference. The self-adhered composite has a smaller binding strength $(1.8878 \pm 0.2859$ $\mathrm{MPa}$ ) compared with conventional composites $(4.43552 \pm 0.49472 \mathrm{MPa})$. From mathematical calculations, self-adhered composites have a binding strength of about $57.4 \%$ lower than those of conventional composites.

The self-adhered composite produces bonding with dental dentine through some quite unique ways. The self-adhered composite used is the Fusiono ${ }^{\circledR}$ Liquid Dentine from Pentron Clinical
Technologies. This composite uses several resins as its organic matrix, ie UDMA, TEGDMA, 4-MET, and HEMA. ${ }^{7}$ The ability to bind with dentine from this self-adhered composite is due to the 4-MET resin content and HEMA.

Based on research on chemical interactions between 4-MET and hydroxyapatite, it is clear that this type of resin has the potential to engage directly. In the study, it was stated that 4-MET resin binds to dental dentin through ionic bonds. This may occur because 4-MET resins have acid properties $(\mathrm{pH} 3-4)$. The negative charge of the carboxyl group on the 4-MET resin will replace calcium phosphate in dental dentine. In addition, the release of these hydroxyapatite particles will cause microporosity on the surface of the dentine, thereby providing a mechanical bond between the composite and dentine teeth. This process will also help the HEMA resin to penetrate into the dentin. Although this bond is believed to be a prerequisite for obtaining a good bond between the restorative material and the dental tissue, the potential of the resulting chemical interaction still plays an important role.

In addition to 4-MET, another ingredient that supports the binding strength of the selfadhered composite is the HEMA resin content. This resin enhances the connective strength that synergizes with 4-MET. In previous studies, dentin teeth applied by HEMA became more easily penetrated by resin monomers. This is one way to increase the composite binding strength with dentin. The composite resin monomer will diffuse into the dentine surface. Then, when the resin polymerizes, a hybrid layer or hybrid layer comprising a mixture of dentin and resin ${ }^{11}$ is formed. This substrate will then bind also to other resins contained in the composite, so this layer serves to unite the matrix resin in the composite with dentin. ${ }^{12,13}$

Although the bond strengths produced by self-adhered composites should be higher, they combine mechanical and chemical bonds, but from this study it is evident that the strength of the self-adhered composite bonds is still lower than conventional mechanically bonded composites alone. What might explain this phenomenon is the difference in the degree of binding strength. Although in self-adhered composites microporosity results from the release of calcium phosphate 
by carboxyl groups in 4-MET resins, but their size is still much smaller than the microporosity formed by the etching process. The difference of acidity level between 4-MET resin ( $\mathrm{pH} \mathrm{3-4)} \mathrm{with}$ phosphoric acid $(\mathrm{pH}<1)$ is assumed as one of the causal factors. In the application process, the self-adhered composite takes 20 seconds before irradiation. This process has a time difference of 5 seconds longer than the etching done for conventional composites that is, for 15 seconds. This is compensated by a lower level of acidity of 4-MET resin compared to phosphoric acid.

Configuration factor or better known as c-factor, has an important role in terms of composite bonding strength to tooth dentin. Clinically, composite clumps have five areas that bind to the dental structure, namely mesial, distal, facial, lingual, and cavity bases. ${ }^{5}$ Because composites undergo shrinkage during the polymerization process, it causes internal stress in the composite fields that bind to the tooth structure. Internal stress will be reduced by the field of composite which is not bonded to the tooth structure. Thus, the wider field of non-bonding composites, the less internal pressure it produces. In this study, the field of composite bonding with the tooth structure is only one part, so there is no significant effect on internal stress.

\section{CONCLUSION}

Based on the results of the research conducted, it can be concluded that, there was a significant difference in the bond strength between selfadhered composites with conventional composites towards the tooth dentine teeth.

\section{REFERENCES}

1. Ferracane JL. Materials in Dentistry: Principles and Applications. 2nd ed. Philadelphia: Wolters Kluwer Health/Lippincott Williams \& Wilkins; 2001. p. 88-100, 135-9.

2. Dhuru VB. Contemporary Dental Materials. New Delhi: OUP India; 2004. p. 57-65.

3. Aschheim KW, Dale BG. Esthetic Dentistry: A
Clinical Approach to Techniques and Materials. 2nd ed. St. Louis: Mosby-Elsevier; 2001. p. 69112.

4. Craig RG, Powers JM. Restoratives Dental Materials. 11th ed. St. Louis: Mosby-Elsevier; 2002. p. 231-80.

5. Heymann HO, Swift EJ Jr., Ritter AV. Roberson, Sturdevant's Art and Science of Operative Dentistry. 6th ed. St. Louis: Mosby-Elsevier; 2006. p. 243-71, 495-524.

6. Anusavice KJ. Phillip's science of dental material. 12st ed. St. Louis: Saunders-Elsevier; 2003. p. 273-99.

7. Fusio ${ }^{\mathrm{TM}}$ Liquid Dentine. 2009. Instruction for Use [cited 2010 Feb]. Pentron Clinical. Available from: http://www.pentron.com

8. Borsatto MC, Catirse ABEB, Dibb RGP, Do Nascimento TN, De Sa Rocha RAS, Corona SAM. 2002. Shear bond strength of enamel surface treated with air-abrasive system. Braz Dent J. 2002;13(3):175-8.

9. Ramos RP, Chinelatti MA, Chimello DT, Borsatto MC, Pécora JD, Palma-Dibb RG. Bonding of self-etching and total-etch system to Er:YAG laser-irradiated dentin tensile bond strength and scanning electron microscopy. Braz Dent J 2004;15 Spec No:SI9-20.

10. Padipatvuthikul $P$, Mair LH. Bonding of composite to water aged composite with surface treatments. Dent Mater. 2007 Apr;23(4):519-25.

11. Suzuki K, Takahashi M, Nakai H. Treatment of dentin by aqueous solution of amino acid derivative-HEMA. Adhesive Dent. 1990;8(1):43-51.

12. Nakabayashi N, Takarada K. Effect of HEMA on bonding to dentin. Dent Mater. 1992 Mar;8(2): p. 125-30.

13. Nakabayashi N. Resin reinforced dentine due to infiltration of monomers into the dentine at the adhesive interface. J Jpn Dent Mater. 1982;1:75-86.

14. Wang T, Nakabayashi N. Effect of 2-(methacryloxy)ethyl phenyl hydrogenphosphate on adhesion to dentin. J Dent Res. 1991 Jan;70(1):59-66. 